\title{
AS FONTES PRIMÁRIAS DO DIREITO: O DEBATE EUROPEU CERCA DE 1850 A 1950
}

\author{
João Maurício Adeodato ${ }^{1}$
}

Resumo: Há um problema semântico, maior do que o habitual, na classificação tradicional das fontes do direito em "primárias" e "secundárias". Um exemplo dessa dificuldade está nas discussões em torno de qual da perspectiva da norma jurídica kelseniana seria primária, qual seria secundária, se aquela referente à conduta ilícita ou a lícita. Este trabalho estuda como esse problema surgiu e foi tratado ao longo da filosofia do direito européia no século XIX.

Palavras-Chave: Fontes Materiais. Fontes Formais. Fontes Dogmáticas.

Abstract: There is a semantic problem in the traditional classification of the sources of law in "primary" and "secondary" sources, wich always depends on the angle of observation. An example os this difficulty lies in the old discussion about which part of the juridical norm could be called primary, according to Kelsen, Cossio or Garcia-Maynez. This paper presents how this appeared and was treated along XIX.th century philosophy of law.

Keywords: Material Sources. Formal Sources. Dogmatic Sources.

\section{INTRODUÇÃO: O CONCEITO DE FONTES PRIMÁRIAS}

$\mathrm{H}$ á um problema semântico, maior do que o habitual, na classificação tradicional das fontes do direito em "primárias" e "secundárias". Talvez pelo próprio relativismo que essa oposição suscita, pois 
sempre depende do ponto de vista aquilo que se considera mais ou menos importante, aquilo que se considera primário ou secundário.

Um exemplo dessa dificuldade está nas discussões em torno de qual perspectiva da norma jurídica kelseniana seria primária, qual seria secundária, se aquela referente à conduta ilícita ou à lícita. No caso da evolução e mudança do pensamento de Hans Kelsen, e envolvendo sua controvérsia com Carlos Cossio, e a deste com Garcia Maynez, a escolha da denominação depende, na interpretação aqui tomada, de verificar se a norma é observada qualitativa ou quantitativamente, havendo argumentos para ambos os lados. De uma visão que aqui será chamada de qualitativa, a norma primária refere-se mesmo à conduta ilícita, pois só aí aparece a coercitividade, tida como o caráter distintivo do direito; com efeito, quando as pessoas se comportam licitamente, não aparece a diferença específica da norma jurídica, pois é impossível afirmar se assim se conduziram por seguirem normas morais, jurídicas ou religiosas. Tampouco basta o conceito genérico de sanção, pois toda norma, incluindo a moral, tem na sanção um elemento essencial (DURKHEIM, 1983). Não é, contudo, o caráter distintivo da norma jurídica o que interessa agora.

No caso das fontes, há os que entendem por primárias as fontes formais mais importantes, de uma perspectiva estatal, como a lei e a jurisprudência, sendo fontes formais secundárias as que delas dependem, como os testamentos e os contratos, cuja validade se dá em função do acordo com as fontes primárias (GARCIA MAYNES, 2005). Segundo essa concepção, primárias são as fontes dogmáticas. Em outra espécie, estariam as fontes materiais, aquele conjunto de conteúdos biológicos, físicos, ideológicos, axiológicos que originam e preenchem as fontes formais. ${ }^{2}$ Assim, o fato de a mulher só poder ter filhos de um mesmo homem a cada gravidez é fundamental para o direito das sucessões, da mesma maneira que são fontes materiais as ideologias dos diversos grupos sociais, a luta de classes, as diferenças culturais.

Como esse fundamento mais remoto do direito é de difícil determinação e manuseio, a dogmática jurídica moderna o afastou de suas ocupações, estrategicamente lançando mão da distinção entre as fontes materiais - ainda sem forma jurídica, campo da filosofia, da sociologia ou da política - e fontes formais - dogmáticas, definidas por meio da escolha de qual das concepções e ideologias em conflito ganhará foros 
coercitivos e será imposta a todas as demais como direito positivo. Assim, toda fonte formal vem de uma fonte material vencedora, mas investigar essas fontes não é função do jurista. De toda maneira, resta o problema retórico: primárias são as fontes mais coercitivas, mais diretamente aplicadas ao caso concreto, como a lei, a jurisprudência, o contrato e a sentença, ou primárias são as fontes dessas fontes, as fontes mais primevas. Tudo depende de onde se observa. Como sempre.

O sentido aqui é o de fontes primárias como fontes materiais, e não dogmáticas.

Assim, a questão de quais as fontes das fontes, as fontes primárias no sentido empregado por Jean Haesaert (1948) e adotado aqui, não abandonam a filosofia do direito e todo estudo mais aprofundado, que se pergunta sobre as causas primeiras do direito positivo, precisa passar por essa temática. Nessa direção, o presente trabalho procura dar ao leitor uma visão mais geral, perfunctória, de diversos autores importantes na modernidade, não com o objetivo de exatamente estudá-los, mas sim de compreender o conceito de fontes primárias ou materiais do direito. Metodologicamente, esses autores servem apenas como paradigmas, ajudando o leitor a compreender suas diferenças e fornecendo uma visão geral de pensadores pouco conhecidos no Brasil.

Feitos esses esclarecimentos preliminares, outra tese que perpassa o presente estudo é tentar mostrar que há algo de constante, comum a todos os autores que se preocupam com o problema da Etiologia Jurídica, com o problema das fontes primárias do direito, da "causa": eles crêem que a juridicidade provém de um princípio superior que se impõe aos seres humanos e que as normas derivadas desse princípio são universalmente válidas e justas. Isso equivale a dizer que esses muitos autores da Teoria Geral do Direito mostram seu acordo sobre a idéia de um direito "natural", para usar a metáfora clássica, no sentido de algo que está acima da vontade humana e de seu poder constituinte originário. As concepções dos diversos autores, porém, variam a respeito do método a ser utilizado: uns procuram a metafísica ou a fé; outros, um método mais empírico e "científico". Mesmo esses últimos, porém, não deixam de se aliar à tradição jusnaturalista, no sentido de que existem fontes prévias, acima das fontes dogmáticas positivas. Todos têm em comum a convicção de que as últimas origens do direito 
não estão na lei, nos contratos, na jurisprudência ou em qualquer das fontes dogmáticas do direito positivo moderno.

Claro que há os que não procuram qualquer princípio superior. São os positivistas que não se preocupam com o problema das fontes primárias, ficando assim de fora deste estudo. Aqui, tentar-se-ão expor as diferentes linhas das concepções não positivistas sobre tais fontes, a fim de que elas possam ser comparadas e compreendidas melhor dentro de seu contexto. Nessa abordagem, será seguido o mesmo plano de trabalho desenvolvido pelo autor de base escolhido, Jean Haesaert, acrescido de críticas e observações. Devido ao destaque do pensamento alemão no período aqui recortado, alguma concentração sobre ele foi inevitável. Estudar o pensamento das principais escolas jusfilosóficas européias na primeira metade do século passado, pela grande influência que exerceram em todo o mundo, certamente ajudará a compreender melhor os debates havidos à época no Brasil e seus reflexos até os dias de hoje.

\subsection{A CONCEPÇÃO SOCIOLÓGICO-CATÓLICA: A TEORIA DA INSTITUIÇÃO}

Hoje parece um truísmo dizer que as concepções religiosas, também muito comuns em povos mais primitivos, permanecem ainda bem atuantes em sociedades reconhecidamente complexas. Aqui vai interessar, mais particularmente, a doutrina do Cristianismo, uma das maiores forças na moldagem da cultura ocidental, mormente na linha do Catolicismo. Convém lembrar que, nas concepções religiosas, o fundamento do direito é a vontade da divindade, vontade que é revelada à autoridade competente para que a interprete e traduza para os fiéis.

Autores mais ortodoxos, como Jean Dabin, entre outros, partem do princípio de que existe uma revelação, na qual a razão humana pode se inspirar e encontrar soluções justas para todos os problemas jurídicos, pois a razão humana é reflexo da razão divina, que perpassa todo o cosmos. A revelação é tida como ato gnoseológico específico, um conhecimento inspirado pela fé e, por isso mesmo, mais digno de crédito.

Georges Ripert detém-se no problema e afirma que o jurista precisa ter presente que o direito vai ser aplicado a uma sociedade de moral cristã, moral esta segundo a qual o ser humano deve tentar 
perfeccionar sua alma, sim, mas, ao mesmo tempo, tem que respeitar o próximo. Tais regras básicas são frontalmente contrárias aos interesses privados de cada um e por isso difíceis de ser seguidas. Para Ripert, há regras jurídicas que não possuem outra base que não uma regra moral, e a regra moral, por seu turno, é embasada em determinada concepção religiosa do universo. Isso não significa que o jurista esteja dispensado de buscar fundamentos históricos para o direito positivo. Mas as regras impostas por meio de uma concepção religiosa e moral do universo são as melhores e mais fortes que podem ser oferecidas ao ser humano. Que razões históricas, por exemplo, poderiam ser oferecidas para justificar a dissolubilidade ou não do vínculo matrimonial? A resposta a essa pergunta é, necessariamente, de base moral e religiosa. A argumentação concentra-se na fé, é certo, mas ela é justificada por seu caráter racional, o qual lhe confere valor universal.

Há, porém, algumas falhas manifestas nesse tipo de concepção, tanto de caráter histórico quanto lógico.

Em primeiro lugar, as regras impostas, mediante uma concepção religiosa e moral do universo, não deixam de ter uma base histórica, incluído aqui o exemplo apresentado a respeito do vínculo matrimonial. Não há que se separar entre explicações históricas e explicações morais, uma vez que o fato de fundo moral é, como todo fato, histórico.

Depois, uma vez admitido que a vontade de Deus se impõe por si mesma, por meio da fé, nada mais há para ser feito ou discutido. Por isso, afastam-se as objeções, a etnologia, a sociologia, a história. $\mathrm{O}$ que existe é a necessidade de chegar a conclusões ortodoxas, de acordo com os dogmas prefixados, o que caracterizaria uma falsa busca, pois já se conhece aonde se quer chegar.

Por outro lado, mesmo abstraindo da civilização humana os demais povos e procedendo-se a uma análise exclusivamente centrada na civilização ocidental, a doutrina cristã não lhe parece constituir o fundamento axiológico na modernidade. Os povos não parecem guiados pelos princípios essenciais do Catolicismo cristão, os quais são francamente rejeitados, o que aparece na lei da mesma forma que na opinião pública: o aborto, a guerra e o divórcio, fatos diários na civilização ocidental, são exemplos disso, mostrando que outras perspectivas de vida conseguem uma adesão tão forte quanto a cristã, expressando a falta de evidências objetivas na tese de superioridade do Cristianismo. 
Invocando uma "razão esclarecida" para a fé, os teólogos caem num círculo vicioso, já que a razão é garantida pela fé e esta pela luz das forças transcendentes. Mesmo essa razão esclarecida cristã é vacilante, bastando, para isso, observarem-se as profundas variações das concepções da própria Igreja ao longo da História, sobre pontos essenciais, como a separação dos poderes secular e temporal (condenada por Pio X e aprovada por Leão XIII, por exemplo) e o casamento. Tal disparidade histórica comprova a variação de conteúdo. $\mathrm{Na}$ realidade, a razão cristã não existe como tal, seu conceito e conteúdo dependem do meio ambiente e ensejam grandes modificações na interpretação dos fenômenos.

Duas falhas de ordem lógica são também manifestas: a razão é considerada insuficiente para resolver as dificuldades da vida social, necessitando da fé e da revelação em sua ajuda. Paradoxalmente, porém, a razão é considerada capaz de convencer os incrédulos, pois a argumentação racional cristã seria irresistível às pessoas esclarecidas, inclusive àquelas desprovidas de fé.

Depois, os princípios cristãos, entre os quais o repúdio à violência, são considerados como os meios mais eficazes para o aperfeiçoamento do ser humano. Mas Ripert, por exemplo, cai em outro paradoxo ao propor o constrangimento dos não-conformistas pela força, meio sempre utilizado em larga escala pela Igreja e por outras instituições fundamentalistas.

Apesar de, em regra hostil à Sociologia, a doutrina católica foi a ela conjugada por meio da teoria da instituição, tal como é apresentada por Jean Delos e Georges Rénard. Afastando-se de seu precursor, Maurice Hauriou, o qual se atém mais ao direito positivo, partindo da instituição, mas permanecendo sociólogo e jurista, aqueles autores baseiam-se na Sociologia, com o fito de ultrapassá-la, numa tentativa de atingir o mundo dos valores, fortalecendo o conceito de institucionalismo. Hauriou define a instituição a partir do conceito de idéia, entendida como um pólo de agregação para o qual não há explicações de origem ou natureza, pois a significação da instituição não ultrapassa sua existência. A existência da idéia é dupla: objetiva, quando considerada em si mesma; e subjetiva, quando captada pelo espírito humano. As idéias objetivas seriam produtos do ambiente social, funcionando o indivíduo como seu elemento de percepção e captação. 
Sob o ponto de vista de Hauriou, poderia ser feita uma síntese entre a Sociologia e o tomismo, o que ele tenta por meio dos conceitos de idéia dominante, como pólo da instituição, de natureza sociológicopositiva e de bem comum, de essência metafísica e sobrenatural. Isso permite absorver a teoria da instituição no tomismo. Para Tomás de Aquino, o bem comum é o fim da sociedade, não intervindo sobre a nação apenas para formar o Estado, mas, também, influenciando sobre as associações para lhes dar forma própria. $\mathrm{O}$ bem comum constitui a mais alta idéia que pode ser percebida por um grupo, a idéia da obra que deve ser cumprida. Ora, a idéia de uma obra comum, desde que endereçada a todos os participantes da empresa, passa a ser o próprio bem comum para esses participantes. Como o bem é comum, a idéia é superior ao indivíduo, transcendente; sendo transcendente e superior, ela é o bem que vem de Deus. Advinda de Deus, a idéia é um bem necessário que se impõe a toda a sociedade. Daí, o direito que realiza o conteúdo do bem comum não pode ser outra coisa senão um direito objetivo e, conseqüentemente, um direito superior aos indivíduos.

Toda essa argumentação repousa sobre um jogo de anfibologias: os institucionalistas dão sentidos metafísicos a idéias e expressões que os sociólogos entendem de modo empírico. Isso porque, de um ponto de vista sociológico, o bem comum se confunde com a idéia diretora da associação, formadora da instituição. Mas isso não torna o bem comum um valor absoluto, pois há um bem comum fundamentalista, um marxista, um liberal e assim por diante.

Mesmo em sua vertente sociológica, a tentativa de fundamentar, objetivamente, a validade da regra de direito tem pontos obscuros. As regras jurídicas, para realizar o bem comum, têm uma função técnica, mediadora, pois é seu objetivo, o valor que elas realizam, que constitui seu fundamento e razão de ser. Além disso, a tentativa de conciliação não se sustenta por ir de encontro às próprias idéias católicas que pretende apoiar, pois a Igreja tem a sociedade em segundo plano, uma vez que está destinada a ajudar o homem na busca de sua perfeição individual para a salvação da alma. 


\subsubsection{Sistemas abertamente metafísicos: Georg Wilhelm Friedrich Hegel, Max Ernst Mayer, Wilhelm Sauer e Julius Binder}

Pode-se definir "metafísica", entre outros critérios, como uma explicação exaustiva e holística da realidade, com perspectivas semelhantes à religião, só que com pretensões de racionalidade universal e rejeição de critérios de revelação. A metafísica encontra-se, assim, em posição desfavorável em relação à religião, porque esta se baseia na fé, em dogmas aceitos como verdades indiscutíveis, enquanto os argumentos metafísicos buscam demonstrar sua verdade, que se apresenta como racionalmente cogente. Historicamente, a metafísica atravessou um período de descrença, diante do progresso da ciência no século XIX, quando as "provas científicas" alcançaram grande relevo. O otimismo logo diminuiu, tanto pela verificação de que aquela concepção de razão era impotente para resolver muitos dos problemas que se colocavam, quanto pelos insucessos políticos e catástrofes ocorridos. Quase todas as concepções metafísicas no período, após o neokantismo, encontram-se sob o signo do idealismo, num claro retorno a Hegel, filósofo de grande importância para bem compreender esse período.

Para Hegel, em sentido bem literal, a única realidade é a idéia, a qual constitui a própria unidade do ideal e do real, do finito e do infinito, da alma e do corpo, do sujeito e do objeto, do essencial e do contingente, assim como da natureza e do espírito e de todos os demais pólos aparentemente opostos. Toda sua teoria baseia-se na identidade entre o real e o racional para explicar a evolução do universo: identificado com o espírito, o ser só se pode desenvolver segundo as leis espirituais. Essa é a lógica de Hegel. O apelo da filosofia hegeliana está justamente na tese de que o estudo do espírito humano passa a ser o estudo da realidade mesma, do universo, lá onde lógica e metafísica se confundem. Como a lógica é uma ciência de conceitos, o desenvolvimento desses conceitos coincide com o desenvolvimento da própria realidade. Observe-se que a estratégia de trabalhar com conceitos e desenvolvê-los logicamente elimina, desde logo, muitos problemas que o exame direto do mundo real poderia suscitar.

O desenvolvimento não é apenas um método na obra de Hegel, ele mesmo é um conceito que inclui e conclui todo o sistema, como diz Haesaert. O processo pelo qual tal desenvolvimento se realiza é 
sempre o mesmo: vai da tese à antítese e daí à síntese. Essa síntese, tendo resolvido a oposição, torna-se o ponto de partida de um novo desenvolvimento e assim por diante. Dessarte, o universo é uma obra organizada de forma simétrica, segundo os princípios internos que o constituíram: não poderia ter sido de outra forma senão essa que apresenta e que o ser humano, como parte integrante dela que é, pode perceber.

A parte mais especificamente jurídica da filosofia de Hegel é principalmente constituída pela antítese entre a "consciência individual" e a "vida coletiva", ou entre o espírito subjetivo e o espírito objetivo. O problema fundamental do direito e da política está na oposição entre indivíduo e sociedade, a qual, em seu fluxo, vai gerar a síntese conciliadora que ultrapassa a perspectiva individualista: o espírito subjetivo, com sua consciência de liberdade, projeta-se como espírito objetivo e realiza essa mesma liberdade, em outros termos, dentro do direito. É no espírito objetivo que o espírito subjetivo se consuma e se completa. O Estado assume o papel de conceito superior, pois constitui a melhor realidade, na qual qualquer conflito é resolvido. Assim, ele deve ser onipotente, superior a cada indivíduo, uma entidade independente. A fonte primária do direito está nesse espírito objetivo que o Estado personifica.

Outro exemplo de uma filosofia do direito metafísica está em Max Ernst Mayer, professor da Universidade de Frankfurt am Main. O autor parte do conceito de "cultura", que considera a expressão real da "idéia de humanidade", a verdadeira fonte primária: a essência da humanidade é tida como puramente espiritual, exteriorizando-se por meio dos valores culturais, os quais dão sentido ao existir do homem. Esses valores são, ao mesmo tempo, criadores e produtos da cultura. São eles que engendram as normas específicas, apropriadas a cada coletividade, segundo seu desenvolvimento cultural. Por isso os ideais de justiça variam.

Mayer afirma que o ideal jurídico, inspirado no ideal cultural de que faz parte, realiza, no direito positivo, de forma concreta, a idéia de humanidade. Pelo que se pode depreender, a idéia em si não teria qualquer força criadora, sendo estéril e ineficaz. Somente quando ela é convertida em ideal, realiza-se efetivamente (LARENZ, 1935). 
Não é fácil perceber um sentido preciso para a terminologia muito peculiar do autor, que toma como assentes diferenças pouco nítidas entre palavras como "idéia", "ideal", "humanidade" etc.

Wilhelm Sauer baseia-se, principalmente, em Hegel, mas procura chegar a uma síntese entre as mônadas de Leibniz e a concepção de cultura de Fichte. As mônadas de Leibniz são recepcionadas como mônadas de valor, essência de todos os entes, menor unidade axiológica que perpassa todo o universo. Essas mônadas constituem a cultura, tipo de organização que ocorre porque as mônadas tendem, naturalmente, na direção dos valores absolutos, ordenam-se em sua direção.

O direito é, então, uma ordenação de mônadas de valor na direção da segurança, segundo o ponto de vista do Estado, poder instituído. Essas mônadas constituem as fontes primárias do direito. Sauer tem a justiça como valor secundário em relação à segurança. Ele próprio classificou sua teoria de "panteísmo crítico", fazendo convergir pensamentos tão diferentes como os de Spinoza e Kant.

Note-se que o autor não utiliza as mônadas de valor como mero método de exposição, como hipótese filosófica de cunho lógico ou mera metáfora, mas as tem como verdadeiras realidades. Isso faz com que sua teoria permaneça idealista, sem qualquer fundamento empírico.

Para Julius Binder, dualista, ao lado do mundo da natureza, infenso ao valor, há um outro mundo que é produto livre da ação humana, merecendo por isso um ângulo específico de observação: é o mundo da cultura, no qual reinam as idéias. O pensamento de Binder pode ser resumido como um criticismo inspirado em Hegel, no qual transparecem as influências de Fichte e Schelling. A aparente semelhança estrutural entre natureza e cultura é uma hipótese que deve ser afastada, pois o mundo da cultura tem um sentido específico que é sua própria condição de possibilidade. O sentido seria uma idéia que dá forma aos objetos e constitui a própria existência deles, pois, como neohegeliano, defende que a idéia é a realidade categorial da coisa: a matéria existe como mero acidente, enquanto a idéia forma a substância das coisas.

Binder pensa diferente dos fenomenologistas, porque o sentido de que falam não vai além das "coisas mesmas" (HUSSERL, 1965), ou seja, é alcançado pela contemplação pura da essência como objeto de conhecimento, abstraindo, assim, a existência real das coisas. Para Bin- 
der, a existência também precisa ser considerada e os objetos resultam não de mera contemplação, mas de uma elaboração intelectual.

Especificamente no campo jurídico, afirma que as idéias possuem duas funções: uma regulativa e outra constitutiva. Regulativa porque são as idéias que verificam se o conteúdo empírico de uma norma é adequado, isto é, determinam para qual porção específica da realidade a norma em questão é válida. Constitutiva porque a idéia é um fator que dá significação à realidade objetiva. Note-se que a idéia não é entendida por Binder como uma categoria kantiana, isto é, um princípio formal que coloca ordem na realidade objetiva; ela é fator também constitutivo e não, como em Kant, apenas regulativo. Binder discorda de Hegel, ao considerar que as idéias não são imanentes ao mundo e, conseqüentemente, não se materializam nos objetos, permanecem fora deles. As idéias funcionam em frente à realidade e não dentro dela. $\mathrm{O}$ espírito assume, então, o papel de hipótese metafísica, necessária ao mundo da cultura.

Disso tudo Binder conclui que a tarefa da filosofia do direito não é a busca do conceito de direito, como é feito tradicionalmente, e sim da idéia do direito. Analisando a concepção corrente, no sentido de que o direito e a norma estariam inseparavelmente ligados, conclui que as normas não constituem as formas de expressão autênticas do direito. A juridicidade de uma norma estaria justamente na circunstância de se referir a uma idéia, a uma idéia de direito. A idéia é que faz da norma uma norma jurídica. Não fica claro o que entende exatamente por idéia, mas certamente a expressão tem sentido semelhante ao que tem em Hegel.

Binder considera que, entre um indivíduo e os demais seres humanos, não existe apenas uma comunidade, no sentido de uma organização psíquica comum, fruto de experiências semelhantes; o sentido da comunidade está também no pensamento e na consciência individuais. Em outras palavras, não se pode separar a idéia individual da coletiva, transpessoal. Daí infere que, para a idéia de direito, não é tão importante o indivíduo isolado, o qual não pode reivindicar direitos subjetivos, já que sua existência só adquire sentido dentro de uma comunidade. 


\subsubsection{Sistemas disfarçadamente metafísicos: François Gény e Georges Gurvitch}

O termo "metafísica camuflada" é utilizado por Haesaert para designar aqueles jusfilósofos que buscam alguma base empírica para suas teorias, mas seu fundamento é, em verdade, metafísico, pois a eventual referência empírica sempre apresenta caráter secundário em relação à parte metafísica.

Para François Gény (1861-1959), a lei, é essencialmente, uma manifestação de vontade e esta nunca é, necessariamente, lógica; o legislador pode ser lógico, sim, mas sempre é também ilógico, o que pode levar a incongruências ou a lacunas dos mais diversos tipos no ordenamento legal. Se a lei é conseqüência, é preciso investigar quais fontes primárias o direito tem a oferecer para sua devida compreensão. Uma importante contribuição de Gény, detalhada em suas duas obras principais (GÉNY, 1919), é o fato de ele chamar a atenção para a "livre investigação científica" como fonte importante para a interpretação do direito legislado.

Chega, então, a sua famosa doutrina, segundo a qual a atividade do jurista se exerce sobre os dois campos que compõem o direito: o dado e o construído. O conjunto de todos os dados são as fontes primárias do direito, enquanto a técnica e a ciência forneceriam o construído. Esses dados independem do processo legislativo e da vontade da lei, que têm caráter secundário, mas impõem direção aos fatos sociais e adquirem força normativa em relação ao comportamento humano. As fontes primárias são suficientemente elásticas para indicar inequivocamente uma direção, sem serem determinantes. Os dados são classificados em quatro grupos:

a) os dados reais ou naturais, isto é, as circunstâncias de fato sob as quais se encontram os indivíduos, tais como sua sociabilidade e suas limitações físicas;

b) os dados históricos, que contribuem para sedimentar os dados naturais e concretizá-los num determinado tempo e espaço, como o costume, as formas de governo ou a guerra, os eventos, de modo geral; 
c) os dados racionais, princípios gerais inferidos pela razão a partir dos dados naturais, os quais têm um caráter necessário e universal. Exemplos são a convicção de que há determinados direitos subjetivos inerentes ao ser humano ou certa concepção da estrutura familiar;

d) os dados ideais, que concentram as aspirações humanas e fornecem os impulsos para o progresso do direito positivo. Essas aspirações tendem ao futuro e a interferir nas circunstâncias fáticas, moldando a realidade, mas são de difícil determinação. Exemplos são a busca do bem e a idéia de que o bem de todos deve ser procurado.

Esses dados se hierarquizam na teoria de Gény, para quem os dados racionais colocam-se no centro das preocupações do jurista, na medida em que respondem pela construção de instituições duradouras. Os dados reais e históricos não conseguem, por si sós, criar regras e os dados ideais intervêm apenas para completar e melhorar, revelando-se tão gerais que, apesar de seu valor absoluto, seu caráter abstrato não permite que sirvam de referência objetiva às necessidades concretas. Outros dados menos gerais têm menos valor absoluto, mas podem ser mais seguramente referidos ao concreto, por exemplo, a idéia de que a vida humana é intangível. Menos gerais ainda e, conseqüentemente, mais precisas, são opções específicas, como considerar condenável a eutanásia.

Dentro desse contexto fenomênico de dados, a técnica jurídica deve construir os meios para que se realizem os fins do direito. Esses artifícios e artefatos criados pelo engenho humano, não apenas os de caráter jurídico, formam o "construído". Exemplos, no direito, são as formas que os atos devem adotar para serem considerados válidos, o conceito de pessoa, o costume jurídico e a importância da lei escrita.

Para Georges Gurvitch, a fonte primária do direito é seu caráter social, o que soa óbvio, mas sua contribuição mais característica está na análise e explicação dessa sociabilidade, vista como um sistema em equilíbrio dinâmico, transpersonalista, e, o que é mais importante, no qual não há lugar para relações de coordenação ou de subordinação, mas somente de integração. A integração constitui a função específica 
do que denominou "direito social". Sua contribuição foi grande para o que se pode denominar uma filosofia do direito do trabalho, ramo ao qual dedicou muita atenção e para cujo caráter tutelar, reconhecido em boa parte das constituições contemporâneas, sua obra contribuiu significativamente.

Esse conjunto social é ativo, no sentido de que dirige sua própria existência, realizando autonomamente sua regulação. A essa regulação autárquica pode ou não ajuntar-se uma regulamentação organizada, a qual, se vier a existir, permanece acessória por não conseguir jamais abarcar completamente as forças autônomas da sociedade. Por isso essa eventual regulamentação organizada, por exemplo, a das fontes dogmáticas do direito moderno, deve conformar-se perante a fonte autônoma e espontânea.

Um ponto básico em Gurvitch é o entendimento de que o direito resulta da natureza, mesmo que seja da "natureza social" do ser humano, diminuindo o papel da vontade circunstancial e empírica na constituição da realidade jurídica. A noção de "fato normativo", essencial em Gurvitch, também demonstra um viés não kantiano, para quem não é possível uma passagem direta do fato à norma, sendo sempre necessária a intermediação da vontade, com seus próprios critérios.

\section{CONCEPÇÕES DE INSPIRAÇÃO CIENTÍFICA}

\subsection{TENDÊNCIA RACIONAL-POSITIVISTA: RUDOLF STAMMLER, FRIEDRICH DARMSTAEDTER E LEONARD NELSON}

Os autores agrupados sob essa denominação procuram retirar uma ordem jurídica apropriada a partir da natureza racional do ser humano como fonte primária do direito.

O neokantiano Rudolf Stammler parte das noções de conceito e idéia do direito. O conceito permite especificar, isto é, definir o que é e o que não é jurídico; ao fazê-lo, o conceito permite relacionar certa

atividade particular com um comportamento "jurídico" global. A idéia do direito, por seu turno, é a noção fundamental que deve servir de parâmetro àquelas atividades que o conceito qualifica como jurídicas. O conceito ressalta da natureza racional, a idéia, ao contrário, do mun- 
do dos fins, axiológico. O fim último do direito seria o querer puro de Stammler, idéia central da juridicidade. Esse querer não se confunde com a vontade individual, mas provém da esfera kantiana do dever ser, configurando um tipo específico de racionalidade humana genérica.

No esclarecimento do conceito de direito, Stammler lança sua conhecida definição de "querer autárquico, vinculatório e inviolável". E ressalta dois princípios na realização da idéia do direito, a justiça, na condição de puras diretrizes formais, ou seja, premissas metodológicas que permitem chegar à solução apropriada para cada caso. Em primeiro lugar, o princípio da consideração, que hoje se poderia chamar de inclusão, segundo o qual cada membro da sociedade tem interesse em ser levado em conta, desde que também considere os demais membros de modo idêntico. Já pelo princípio da colaboração, o fim coletivo prevalece e todos cooperam para a consecução de um objetivo comum. Nisso consistiria a justiça na doutrina de Stammler (STAMMLER, 1970).

As críticas feitas à sua filosofia assemelham-se àquelas dirigidas a Kant e à sua concepção formalista de ética. Um conceito de justiça como puro princípio metodológico não consegue fornecer diretrizes de conduta, pois as categorias lógicas não são compatíveis com determinações de conteúdo ético.

Friedrich Darmstaedter vai de encontro à doutrina corrente em seu tempo (e ainda hoje) sobre os caracteres distintivos da norma jurídica, ao procurar demonstrar-lhe a diferença específica em relação às demais ordens normativas. Quando os seres humanos se inter-relacionam, a norma parece ser heterônoma, mas o equilíbrio social existe com base em seu caráter autônomo, isto é, porque a grande maioria das pessoas se submete a ela de livre e espontânea vontade. Só quando abrigadas na legislação positiva é que as normas se revestem de seu caráter de heteronomia, o qual é assim atribuído pelo legislador. Daí a necessidade de distinção entre o direito e a ordem jurídico-positiva: o direito é equilíbrio dentro da relação social, uma vez que cada relação social possui, em si mesma, pelo menos em potência, sua norma jurídica apropriada. Essa norma é produto da aplicação da razão prática àquela determinada relação. A lei, como fonte secundária do direito, vem posteriormente (DARMSTAEDTER, 1925). 
Desse modo, a ordem jurídica positiva é composta por meras volições do legislador: ela não cria as normas de direito, podendo, quando muito, reconhecê-las e promulgá-las. Não é o ordenamento que determina se uma norma é jurídica ou não, mas é a norma jurídica, preexistente, que diz se determinado ordenamento é ou não dotado de caráter jurídico. Daí se conclui que a juridicidade é conferida mediante uma postura moral, pois só a lei moral liga-se a si mesma, a norma legislada só obriga se emanada dessa razão moral prática. Em suma, Darmstaedter reporta-se a um direito natural antropológico: o ser humano pode retirar de sua razão prática as regras a uma coexistência justa e segura.

Pode-se objetar que os acontecimentos históricos não parecem confirmar a teoria de Darmstaedter, pois regras, aparentemente contrárias a qualquer consideração racional, frutos do arbítrio e da tirania, são freqüentes ao longo da História. No mesmo sentido, essa atitude moral geradora do direito tem se mostrado bastante variável e paradoxal, contestando a segura objetividade pregada pelo autor.

Leonard Nelson, à semelhança de Kant, publicou uma Crítica da razão prática. Interessava-se por Pedagogia, Lógica e Matemática, além de Ética e Filosofia, e também escreveu sobre democracia.

Ele parte de uma distinção básica: a teoria das fontes do direito, para ter caráter científico, precisa ser dividida em uma teoria formal, que procura especificar que condições específicas uma situação deve apresentar para ser considerada como relação jurídica e material, a qual fornece os meios para construir o conteúdo da regra e aplicá-la à situação concreta.

Do ponto de vista formal, o direito, movido pela necessidade prática, estabelece critérios para limitar a liberdade recíproca das pessoas. Do ponto de vista material, indispensável para que a norma não permaneça vazia e sem fundamento, a regra prática está no axioma "a justiça é o direito". A justiça é entendida como igualdade individual, não igualdade de fato, como um princípio de conveniência que determina que os sujeitos de direito, quando se inter-relacionam, tratem-se como iguais entres si.

O propósito de Nelson (1972) é encontrar um critério objetivo para a conduta, algo que determine que valores são pertinentes, que 
valores não o são. Além da vaga noção de justiça, Nelson apela para o que denomina "princípio ideal do direito", a dignidade humana. $\mathrm{O}$ conteúdo dessa dignidade humana seria o ideal comum dos indivíduos razoáveis, a tentativa de autodeterminar-se racionalmente.

Algumas dessas afirmações podem parecer truísmos a olhos contemporâneos, mas tiveram relevância nos debates da época.

\subsubsection{Tendência histórica}

Começa a reação dentro do próprio positivismo, em seu sentido mais amplo, empiricista, mas não legalista, contra a Escola da Exegese francesa. Concorda com a Exegese, na medida em que procura eliminar quaisquer resquícios do jusnaturalismo transcendente, mas dela se afasta ao recusar a lei como fonte principal do direito.

As concepções historicistas pretendem descartar qualquer elemento não positivo (não empírico) na busca pelas fontes primárias do direito e defender uma teoria exclusivamente embasada na observação, o que lhe forneceria status científico. Elas admitem que, quando se deduz, a partir de certas circunstâncias de fato, as conseqüências lógicas implícitas nessas circunstâncias, chega-se, necessariamente, a esta ou aquela norma. Ao lado da História, da Sociologia e da própria tendência jurisdicista, a Biologia e a Psicologia foram as ciências naturais que mais influenciaram essas concepções.

Claro que aqueles que recusam a possibilidade de passagem do ser ao dever ser, de viés kantiano, rejeitam também as concepções historicistas, e Jean Haesaert parece ser um deles.

A tendência histórica deita raízes na Escola liderada por Friedrich Carl von Savigny, continuada, principalmente, por Georg Friedrich Puchta e Georg Beseler. Esses autores defendem que o direito só pode ser cumprido de um ponto de vista histórico e que ele é um produto da "alma coletiva", ou "espírito do povo", desenvolvendo-se de modo "orgânico". O direito se faz, ele não é feito. Essas não são meras metáforas, devendo ser entendidas bem literalmente. Ressalte-se que o próprio Savigny é mais reservado que seus seguidores na personificação da alma coletiva e do Volksgeist. 


\subsubsection{Tendência sociológica: Karl Marx, Léon Duguit e Edouard Lambert e a Escola do Direito Livre}

Marx e muitos de seus discípulos têm sido criticados por tentarem racionalizar, deterministicamente, a História. Para os marxistas, com efeito, sob a organização produtiva da sociedade, as pessoas são submetidas a relações específicas, as quais são inevitáveis e independentes da vontade humana, correspondendo a certo grau de desenvolvimento na infra-estrutura econômica da sociedade, que determina as superestruturas jurídica e política. É a existência social do homem que condiciona sua consciência e não o contrário, é o modo de produção dos valores materiais que dirige os processos políticos e sociais em geral. Isso significa que há, na escatologia marxista, um desenvolvimento fatal da História na direção de uma sociedade igualitária, passando por vários conflitos sociais, dentre os quais a luta de classes.

Inspirado em Hegel, Marx entende que o objeto de conhecimento não se oferece de forma constante e cabe ao ser humano adaptar-se a ele. Muito pelo contrário, o conhecimento é resultado de uma síntese contínua entre objeto e sujeito, interativa, em um processo "dialético", no sentido de que essa influência mútua jamais se completa. Assim é que as fontes primárias do direito serão resultados inevitavelmente, mutantes desse processo. Com essa ressalva, é possível estudá-las.

Hegel havia considerado os Estados-nações como os pólos da evolução dialética da História, elementos que Marx substitui pelas classes sociais em continuada oposição. Opondo o feudalismo, comandado pelos proprietários da terra, ao capitalismo, representado pelos industriais, Marx chega à síntese do socialismo, conduzido pela classe dos trabalhadores assalariados. Essa síntese vai ser a tese para novas antíteses e assim por diante.

Sua influência no curso das idéias políticas é talvez ainda maior do que sob a perspectiva propriamente filosófica e dificilmente será exagerada. O número de revoluções, partidos políticos, escolas, debates que invocaram as idéias de Marx atesta estatisticamente sua importância. Mas os fatos históricos, pelo menos no que pode ser observado dentro do lapso temporal até os dias de hoje, não parecem confirmar esse determinismo. Apenas para dar um exemplo, as classes médias, longe de desaparecerem, recobram novo vigor econômico em sociedades nas 
quais se haviam enfraquecido, como na Rússia atual. Pode ser que esse tempo de século e meio seja um recuo na "espiral da História", só o futuro dirá; hoje, contudo, o materialismo dialético comunista parece mais ser parte de uma ideologia revolucionária do que resultado da fonte primária constituída pela estrutura econômica. E o capitalismo tampouco se mostra moribundo, tomando sempre novos fôlegos e estratégias em sua exploração do trabalho.

Duguit e Lambert foram pensadores significativos no sociologismo francês, ao lado de Durkheim, e mais dedicados do que ele especificamente ao direito. Para eles, a sociedade está submetida a um mecanismo rigoroso, a cujas regras todos os fenômenos e todos os indivíduos obedecem. A observação estatística passa a ser o método sociológico por excelência. Com influências de Augusto Comte e Leon Bourgeois, também procuram nos fatos sociais as fontes primárias do direito.

A moral e o direito são dessa ou daquela maneira porque as condições nas quais vivem os homens não permitem que sejam de outro modo e só se modificam quando se alteram as condicionantes fáticas da sociedade. A ciência deve dividir as regras sociais em construtivas, que seriam as fontes formais do direito, colocando a lei em plano secundário; e normativas, os fatos sociais, legitimadores das instituições positivadas pelo Estado.

Daí que o jurista precisa prender-se unicamente aos fatos, desprezando a metafísica. Esses fatos são as necessidades comuns, a troca de serviços, as diferentes aptidões, em suma, a solidariedade entre os participantes. Dentro da solidariedade por semelhança ou por divisão do trabalho, não parece haver propriamente diferença entre as fontes do direito e da moral para essa corrente: caso se chamem regras de direito os imperativos que se constituem como condição essencial para a manutenção e o desenvolvimento da sociedade, a diferença está apenas no fato de que as ditas regras morais são seguidas menos atenciosamente e por menor número de indivíduos que as jurídicas (LAMBERT, 1903).

Os adeptos da Escola alemã do "direito livre", na mesma linha, procuram, nos fatos sociais, as fontes primárias do direito. A Sociologia assume aqui o papel de ciência garantidora da objetividade do direito, em lugar da História sugerida por Savigny e seus seguidores. A Freierechtsschule ajuda a firmar o conceito de "positivismo sociologista" na 
teoria do direito, na medida em que defende a idéia de que todo direito é positivo, mas o direito estatal é apenas uma parte dessa realidade.

Diferentemente da Sociologia clássica, porém, que se assume como uma ciência causal, é importante ressaltar que a Escola do Direito Livre a considera uma ciência normativa. Esse ponto traz uma peculiaridade importante para compreender as contribuições de autores como Eugen Ehrlich e Hermann Kantorowicz. O direito estatal não pode ser único nem superior, uma vez que a principal tarefa dos juristas refere-se justamente a encontrar princípios que permitam avaliar, completar, desenvolver ou recusar o direito estatal.

O grande problema com a doutrina das fontes primárias dessas correntes é detectar os fatos sociais e os princípios que condicionariam todo direito. Como as correntes sociológicas da época, não se preocupam muito com a emancipação gnoseológica do direito. Os conceitoschave são vagos, inclusive o de "fato social", faltando precisar o sentido de noções como luta de classes, alma coletiva, solidariedade, direito da sociedade e tantas outras.

O papel dessas tendências para a teoria do direito foi importante no combate ao excesso de conceitualismo, já criticado por Jhering (ADEODATO, 2002), ao dogmatismo legalista e estatalista das Escolas da Exegese e Pandectística.

\subsubsection{Tendência biologista: Helmut Nicolai e Maurice Hauriou}

Helmut Nicolai pode ser considerado o mais extremado daqueles filiados a essa tendência, defendendo claramente uma doutrina racista do direito, a qual encontrou eco não apenas político, mas também acadêmico e filosófico no mundo ocidental da época, perpassado de idéias de eugenia.

O direito é congênito, ensina Nicolai. Ele nasce, assim como a moral, do sentimento da coletividade, sentimento este que constitui um fato natural ou, mais precisamente, um fato biológico. Cada raça tem seu direito, uma vez que cada raça é biologicamente constituída de maneira diferente das demais, é a óbvia conclusão. O direito é tão determinado biologicamente quanto a cor dos cabelos ou a forma do nariz.

A partir daí, deduzem-se as regras que se coadunam com a justiça e qualquer norma jurídica que contrarie as fontes primárias do "espí- 
rito da raça" é nociva e deve ser eliminada. É importante notar que, para Nicolai, o primeiro objetivo do direito deve ser a pureza racial, tanto física quanto moral, pois a mestiçagem não é natural e precisa ser combatida e eliminada, cabendo ao direito penal, por exemplo, defender a sociedade contra tudo aquilo que não for naturalmente puro, biologicamente determinado.

Sobre essa base, Nicolai conclui que o costume jurídico "natural", qual seja, aquele que espelha fielmente a comunidade, constitui-se na fonte mais garantida do direito e o eventual legislador é tido como mero tradutor seu. A lei só deve obrigar o juiz se estiver de acordo com o direito espontâneo, infinitamente mais vasto que o direito estatal. Dessa forma, um governo nunca é justo em si mesmo, somente como expressão de poder: o verdadeiro direito provém de fontes primárias espontâneas e superiores (NICOLAI, 1933). Ao fundar seu direito espontâneo na pureza racial, Nicolai, evidentemente, pregou a necessidade de exclusão de judeus, mestiços e mesmo de estrangeiros da Alemanha.

Maurice Hauriou, por seu turno, nega o viés racista e vê mais sentido em fundamentar sua filosofia na noção mesma de "ser humano biológico", tendo a seu favor o fato de o direito manifestar-se de modos semelhantes nos povos mais díspares racialmente. O conceito de raça é, mesmo biologicamente falando, uma imprecisa subdivisão, uma mera variação biológica dentro da espécie humana. Mesmo sem ter conhecido os avanços da ciência genética hoje, Hauriou desconfia do próprio conceito de "raça" e recusa qualquer concessão nesse sentido.

É na espécie humana que Hauriou toma o ponto de partida: tudo o que é relativo à espécie terá a mesma universalidade que a própria idéia de espécie abarca, englobando todos os elementos componentes, como os seres humanos e as sociedades. A lei de comportamento deve ser deduzida da espécie, do "estado de justiça" do homo sapiens, isto é, da essência moral do homem.

Mas, por ter desobedecido às leis de Deus, no paraíso, o homem foi apartado do estado de justiça em que se encontrava e reduzido à condição intermediária de vislumbrar o ideal de justiça e não poder realizá-lo completamente. Apesar de esse ideal de justiça ser comum a toda a espécie e apresentar a mesma orientação, a adaptação dos indivíduos e dos povos a essa lei tem sido de incrível variabilidade, 
alguns se aproximando mais, outros se distanciando. Demonstrando sua tendência liberal francesa, Hauriou prega que o poder social deve ser convocado, se possível, a aproximar as pessoas da lei ideal, com o máximo de liberdade e o mínimo de constrangimento.

Pode-se, então, concluir que Hauriou retira arbitrariamente do conceito natural e biológico da espécie homo sapiens, em si destituído de conteúdo moral, uma essência ética praticamente invariável em suas manifestações fundamentais. Mais ainda, por fim, as considerações metafísicas de Hauriou e sua base ética, de conteúdo humanista, podem parecer estranhas a uma base biológica como essa, mas assim são seus argumentos.

\subsubsection{Tendência psicologista: Hugo Krabbe, Roelof Kranenburg e Hermann Isay}

Os autores filiados a essa tendência, ao analisar as fontes primárias do direito, procuram provar que a "alma" humana contém uma disposição particular que, ditando a todos um comportamento homogêneo, faz o direito repousar sobre uma base objetiva, de cunho psicológico, a qual permite distinguir justo e injusto.

Hugo Krabbe explica a formação do direito a partir do que denomina "consciência jurídica", procedendo a uma análise psicológica do ser humano e concluindo que o direito deve preencher dois requisitos para ser intrinsecamente justo: em primeiro lugar, não pode simplesmente partir da vontade de alguém, pois necessita de objetividade e não pode apoiar-se em elemento subjetivo; em segundo lugar, como a finalidade do direito é regular à atividade humana, o conteúdo da regra jurídica precisa corresponder à "natureza espiritual" do ser humano. Em suma, quando se toma uma determinada norma e se quer investigar se ela é efetivamente uma norma jurídica, é necessário observar se sua base se assenta no sentimento que o ser humano tem do direito, o que Krabbe denomina "consciência jurídica". Esse embasamento, ou "enraizamento", na expressão do autor, é um fato psicológico. Tal sentimento jurídico sobrepõe-se aos indivíduos da mesma maneira que o sentimento moral, estético ou religioso: ele independe da vontade de cada um e dá origem às normas positivas, também de validade objetiva (KRABBE, 1930). 
Surpreendentemente, a conclusão de Krabbe não é individualista, mas sim democrática, pois afirma que o critério para distinguir o verdadeiro do falso direito é a maioria: de forma otimista, afirma que a "consciência jurídica", entendida psicologicamente, conduz cada um a aquiescer perante a opinião majoritária.

Roelof Kranenburg diz utilizar apenas o método positivo da observação e pretende um critério geral e objetivo para apreciar os diferentes juízos de valor presentes na comunidade, confrontando as circunstâncias em que tais juízos se formam e expressam. Apesar do fundo comum, sua metodologia é bem diversa da de Krabbe. Kranenburg quer se circunscrever aos juízos de valor que dão origem ao direito, partindo do estudo dos contratos, dos direitos reais, em suma, das instituições e figuras jurídicas. E chega ao seguinte critério geral, base, em sua opinião, de todas as instituições: "Qualquer membro da comunidade jurídica é, no que concerne à repartição das condições de prazer ou de desprazer, igual e equivalente; já que ele não criou por si mesmo as condições de um prazer ou de um desprazer particular, a cada um cabe o tanto de prazer ou de desprazer para o qual criou as condições". Essa seria a norma suprema da consciência jurídica, pois a repartição do que cabe a cada um é função precípua do direito e todas as normas jurídicas têm sua base nessa norma psicológica básica (KRANEMBURG, 1939).

Vê-se que tanto Krabbe quanto Kranenburg baseiam-se em uma mesma noção de instinto psicológico como realidade cognoscível.

Hermann Isay tampouco procura as fontes primárias da ordem jurídica no conjunto das normas emanadas do legislador. Seu fundamento psicológico é concentrado na figura do juiz, pois o direito é formado pelas decisões dos tribunais, construções de sentenças no caso concreto. Para Isay, o juiz primeiro decide e depois tenta justificar a decisão, fundamentando-a no ordenamento. Para não cair no irracionalismo relativista, ele defende a idéia de que, embora a fonte das decisões seja uma espécie de pensamento emocional, tal pensamento não é unicamente de natureza individual, pois contém também elementos sociais próprios, guiados por normas da razão prática.

Pode-se notar a semelhança entre a concepção de Isay e aquela dos realistas americanos, a exemplo de Karl Llewellin e Jerome Frank. 
Todos se prendem a uma concepção estatalista do mundo jurídico, uma vez que a máquina dos tribunais é sempre necessária na concreção do direito. Esquecem as múltiplas facetas que o direito apresenta, independentemente dos tribunais, legisladores ou mesmo Estados estabelecidos. Muitos problemas jurídicos são resolvidos sem que sejam levados aos tribunais, mas é interessante observar a pouca importância dada por Isay à lei (isay, 1970).

\subsubsection{Tendência jurisdicista: Josef Schwering}

Esse autor busca as fontes primárias no próprio direito, sem auxílio de concepções oriundas de outros campos do conhecimento, os quais, se utilizados, devem ter função meramente suplementar.

Schwering prega uma "história natural do direito". Esta se manifestaria nas diversas instituições jurídicas, tais como, a família, a soberania, a propriedade e outras. As transformações que essas instituições vêm sofrendo ao longo da História indicam um sentido: basta que o jurista o siga para obter o direito formado naturalmente, ponto último e atual de uma realização progressiva em contínua evolução. Todo o esforço desse autor se concentra em demonstrar essa constância na evolução histórica do direito, em que pese sua variabilidade de manifestação.

No mesmo sentido, defende que, pelo menos os povos civilizados, todos estão de acordo quanto à essência de determinados institutos jurídicos; daí não é difícil concluir pela possibilidade de um direito intrinsecamente justo (SCHWERING, 1911). Muitos exemplos históricos são, então, invocados por ele para demonstrar esse fio condutor, ainda que as culturas orientais sejam deixadas de lado.

\subsection{A FENOMENOLOGIA: ADOLF REINACH, GERHART HUSSERL E FRITZ SCHREIER}

O método fenomenológico, cujas bases podem ser encontradas nas obras de Edmundo Husserl e Sören Kierkgaard, consiste em observar um determinado objeto, despindo-o de seus aspectos circunstanciais, por intermédio da chamada redução eidética, para observar apenas sua essência ou "eidos". A redução seria uma operação abstracional do intelecto, por meio da qual se vê como o objeto essencialmente é. 
Vários autores utilizaram-se do método fenomenológico na busca das fontes primárias do direito.

Adolf Reinach quer encontrar a essência das instituições jurídicas empregando o método de Husserl no estudo das propriedades necessárias que os objetos apresentam, as bases a priori dessas instituições. $\mathrm{O}$ direito positivo não cria seus institutos mas, literalmente, os encontra, afirma ele; o crédito e a obrigação, por exemplo, possuem uma existência independente de qualquer ordenamento jurídico e de qualquer conhecimento. Apresentam uma "objetividade transcendental" em seu existir, indiferente às formas que lhes empresta o direito positivo. A objeção central a esses argumentos está na dificuldade de separar o método fenomenológico do próprio direito positivo, o fenômeno em questão, o que, como dado empírico, contraria o apriorismo de Reinach. Outra objeção diz respeito a uma eventual infidelidade ao método fenomenológico de Edmund Husserl.

Gerhart Husserl começa por admitir que o direito é uma realidade positiva e temporária. Embora a vontade realize o direito, a validade deste se torna independente da vontade daqueles que o criaram. A validade, então, não é temporal e fixa-se na consciência como um dado transcendente. O problema do filósofo está justamente em saber como o caráter efêmero da vontade e das normas jurídicas positivas se relaciona com o caráter transcendente de sua validade.

O direito vale de uma vez por todas, intemporalmente, mas tem a possibilidade de entrar no curso da História e do tempo ao ser positivamente aplicado. $\mathrm{O}$ juiz ou legislador vai buscar no mundo extemporâneo do direito, intrinsecamente válido, a proposição a ser aplicada concretamente dentro daquelas realidades criadas pela vontade e situadas na corrente natural do tempo. Eles criam o direito concreto ao temporalizar, na lei e na sentença, aquela norma que vale abstratamente. Por intermédio dessa fórmula, Gerhard Husserl pretende explicar a transcendência do direito, sua positividade e as relações entre os dois mundos.

Fritz Schreier parte de premissa semelhante, mas chega a conclusões diametralmente opostas. Para ele, as normas jurídicas existem independentemente do legislador, o qual não as cria, mas apenas as descobre, a exemplo do que ocorre com as leis matemáticas. Apesar dessa existência ideal e independente, as normas jurídicas não possuem 
validade essencial, pois é o legislador quem lhes atribui a validade, ao escolher algumas em lugar de outras.

A tese de Schreier suscita um impasse de ordem lógica: se as normas têm existência própria e tendem por si mesmas a se realizar, o fato de existirem implicaria uma validade intrínseca, não somente existência. Se isso não acontece, a norma jurídica seria simplesmente uma proposição apresentada de forma normativa, jamais uma diretiva concreta de conduta humana, como pretende o autor.

\section{INTERPRETAÇÃO DO DIREITO NATURAL E CONCLUSÃO}

Com essa rápida retrospectiva na história das idéias jurídicas em torno da temática das fontes primárias do direito, observa-se que o pensamento europeu, até meados do século XX, constitui um microcosmos do pensamento ocidental. Com os olhos de hoje, isso se revela no fracasso de todas as teorias que tentaram fixar um conceito permanente de direito, infenso a variações de tempo e espaço. As soluções mais recentes não parecem ter melhor sorte e as tentativas de justificar normas superiores às positivas, mediante dados objetivos, parecem desvanecer-se. A experiência já vem há vinte e cinco séculos e o insucesso demonstra a ineficácia do esforço.

Mas, em outro sentido, apesar dos aparentes fracassos filosóficos, há aspectos positivos no sucesso paradoxal de teorização da política, por exemplo, pois é em doutrinas como aquelas expostas aqui que tomou apoio o desenvolvimento do direito constitucional, do direito internacional e da legislação trabalhista. Além disso, como já ponderaram Nicolai Hartmann e Wilhelm Dilthey, o sentido próprio da investigação filosófica consiste mais na perspectiva histórica sobre seus problemas do que propriamente na diversidade e controvérsias sobre suas eventuais soluções (HARTMANN, 1965).

O que se revela mais interessante é que, se o direito, intrínseca ou naturalmente justo, não se funda nessas premissas oferecidas ao longo de tantos séculos, todas essas filosofias têm em comum a idéia de que as fontes primárias do direito não estão nas manifestações validadas pela dogmática jurídica, essas sempre de caráter imediato, mas secundário. As fontes formais dogmáticas são invariavelmente vistas como "resultado", "produto" de algo mais primário, ainda que 
não haja acordo quanto à "natureza" desse algo. Assim, isso que se tem denominado o direito natural parece pertencer inteiramente à esfera prática e não à do saber em seu sentido estrito, pois suas razões e construções são todas basicamente destinadas à ação, nascidas das necessidades do contexto social.

Daí que esses sistemas teóricos surgem e se desenvolvem em épocas conturbadas, nas quais a aspiração por um direito novo se faz presente. A intuição comum de uma norma transcendente aparece com toda a força, sendo chamada a corrigir as falhas do direito positivo. Onde o direito positivo se mostra insatisfatório, as fontes primárias revelariam o direito completo e justo. Além das necessidades de ordem política, a idéia de fontes primárias também responde a anseios filosóficos atávicos. O ser humano parece sentir um reclamo interior por parâmetros de comportamento que não dependam da vontade do poder jurídico-político e de suas regras positivas.

Daí que essas doutrinas sofrem influências de cada época, adaptam-se a certa "moda" social, indo da teologia à metafísica e desta à ciência. Tais teorias, dessa forma, utilizam-se das mesmas premissas e chegam a conclusões totalmente opostas. O omnis potestas a Deo, por exemplo, justificou a tirania, a solidariedade dos direitos do homem, a supremacia do Estado. Assim, a idéia de direito natural parece constituir uma reação pró ou contra a ordem positiva vigente.

Para que ele se revele, é necessária uma ordem social na qual o indivíduo se manifeste em relação à sua própria consciência, assumindo ser distinto da sociedade. Em outras palavras, é preciso existir a noção de indivíduo. Ambas as idéias são conexas e de grande importância na civilização ocidental: o direito natural e o indivíduo.

O exemplo de Haesaert é ilustrativo: Agamenon, rei da Grécia, nem por um momento discute as ordens recebidas dos deuses, mesmo sendo tais ordens reveladas pelo profeta Calcas, de quem não gostava. Quando Agamenon toma Briseida de Aquiles, este, apesar de increpálo e chorar desconsolado, cede às leis dos deuses e do rei. Já Antígona, alguns séculos depois, opõe-se sem hesitação às leis do tirano Creon. Isso não ocorre porque Antígona era mais corajosa que Aquiles ou Agamenon: é que entre Homero e Sófocles já havia começado a aparecer a noção de indivíduo. 
Essa visão mais histórica e pragmática concentra-se sobre a idéia de que as fontes primárias e naturais do direito representam alguma reação do indivíduo diante dos constrangimentos sociais a que está submetido. Sem chegar a afirmar que o direito natural é mera ideologia, produto de infra-estruturas econômicas, pode-se sugerir que o direito natural é um recurso daqueles que se sentem de qualquer forma oprimidos pelo direito positivo. O direito natural é uma reação do indivíduo e dos grupos sociais contra essa ordem que resiste a suas individualidades.

\section{REFERÊNCIAS}

ADEODATO, João Maurício. Ética e retórica: para uma teoria da dogmática jurídica. São Paulo: Saraiva, 2002.

AFTALIÓN, Enrique; VILANOVA, José. Introducción al derecho. 2. ed. Buenos Aires: Abeledo-Perrot, 1998.

DARMSTAEDTER, Friedrich. Die grenzen der wirksamkeit des rechtsstaates. Heidelberg: Carl Winter, 1930.

. Recht und rechtsord: ein beitrag zur Lehre vom Willen des gesetzgebers. Berlin/Gr6unewald: Rothschild, 1925.

DURKHEIM, Emile. Lições de sociologia: a moral, o direito e o Estado. São Paulo: T. A. Queiroz; EDUSP, 1983.

GARCIA MAYNES, Eduardo. Introducción a la lógica jurídica. México: Fondo de Cultura Económica, 1951.

GENY, François. Méthode d'interprétation et sources em droit prive positif (1899). Paris: Librairie Générale de Droit et Jurisprudence, 1919. v. 1.

HAESAERT, Jean-Polydore. Théorie génerale du droit. Bruxelles: Brulant, 1948.

HARTMANN, Nicolai. Zur grundlegung der ontology. Berlin: Walter de Gruter, 1965.

ISAY, Hermann. Rechtsnorm und Entscheindung. Alaen: Scientia, 1970.

KRABBE, Hugo. Kritische darstellung der staatslehre. Den Haag: Nijhoff, 1930.

KRANENBURG, Roelof. Political theory (Studiën over Recht en Staat). London: Milford, 1939. 
LAMBERT, Edouard. Études de droit commun legislative. Paris: Giard \& Brière, 1903.

MAYER, Max Ernst. Rechtsphilosophie. Berlin: Springer, 1926.

NELSON, Leonard. Recht und staat. Hamburg: Meiner, 1972.

NICOLAI, Helmut. Rasse und recht. Berlin: Hobbing, 1933.

SALDANHA, Nelson. Da teologia à metodologia: a secularização e crise do pensamento jurídico. 2. ed. Belo Horizonte: Del Rey, 2005.

SCHWERING, Josef. Das grundproblem der rechtsreform. Berlin: Rothschild, 1911.

WOLF, Erik. Das problem der naturrechtslehe. 3. ed. Karlsruhe: C. F. Muller, 1964.

\section{NOTAS}

1 Mestre e doutor pela Universidade de São Paulo; pós-doutor pela Fundação Alexander Von Humboldt na Universidade de Mainz; professor titular da Faculdade de Direito do Recife; pesquisador 1-A do CNPQ.

2 Um exemplo desse sentido está em AFTALIÓN, Enrique; VILANOVA, José. Introducción al Derecho. 2. ed. Buenos Aires: Abeledo-Perrot, 1998, p. 632. 